\title{
Ulnar nerve lesions associated with the carpal tunnel syndrome
}

\author{
L. SEDAL, J. G. MCLEOD ${ }^{1}$, AND J. C. WALSH \\ From the Department of Neurology, Royal Prince Alfred Hospital, Sydney, Australia
}

SUMMARY Electrophysiological studies were performed on median and ulnar nerves in 234 cases of carpal tunnel syndrome. Abnormalities of the ulnar nerve sensory action potential were found in $39.3 \%$ of cases. The amplitude of the ulnar nerve sensory action potential was related to the amplitude of the median nerve sensory action potential, and to the median nerve motor conduction velocity in the forearm. The findings suggest that in a significant proportion of patients with carpal tunnel syndrome, a more generalized subclinical neuropathy may be present.

The association of ulnar nerve abnormalities with carpal tunnel syndrome has received little attention. In performing routine diagnostic nerve conduction studies in patients with the syndrome, an appreciable incidence of such abnormalities was noted. This stimulated a review of all patients with carpal tunnel syndrome studied over the past five years with particular emphasis on the frequency of ulnar nerve abnormalities and their significance in the pathogenesis of the syndrome.

\section{METHODS}

SUBJECTS There were 234 cases of carpal tunnel syndrome in the series. These comprised 214 patients, 20 of whom had bilateral abnormalities; 119 of the patients were women and 95 were men. Their ages ranged from 19 to 87 (mean, 54) years. Thirty-four control subjects were also studied in whom there was no history or physical sign of neurological disease nor of systemic disorders known to predispose to neuropathy. Their ages ranged from 18 to 77 (mean, 47) years.

The criteria used for the diagnosis of carpal tunnel syndrome were a history or physical signs of carpal tunnel syndrome together with one or more of the following three electrophysiological abnormalities (Gilliatt and Sears, 1958): (1) a median motor latency at the wrist greater than $5.0 \mathrm{msec}$; (2) a median sensory latency at the wrist greater than

\footnotetext{
1 Reprint requests to: Dr. J. G. McLeod, Department of Medicine,
} University of Sydney, N.S.W., Australia, 2006.

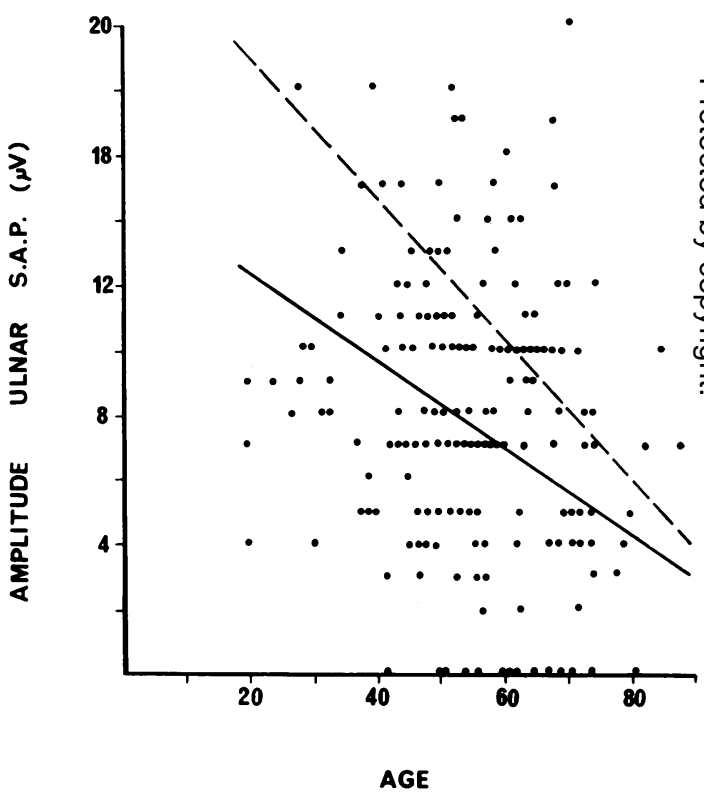

FIG. 1. Relationship of amplitude of sensory action potential of ulnar nerve to age in patients with carpal tunnel syndrome. Solid line: regression line for carpal tunnel syndrome. Interrupted line: regression line for controls.

$4.0 \mathrm{msec}$; (3) an amplitude of the median sensory action potential at the wrist of less than $8 \mu \mathrm{V}$.

Patients were included only if they presented clinically as cases of idiopathic carpal tunnel syndrome. Patients were excluded from the series if 
TABLE 1

RESULTS OF NERVE CONDUCTION STUDIES IN CONTROL SUBJECTS AND PATIENTS WITH CARPAL TUNNEL SYNDROME

\begin{tabular}{|c|c|c|c|c|c|c|c|c|}
\hline & \multirow{2}{*}{\multicolumn{2}{|c|}{$\begin{array}{l}\text { Motor latency from } \\
\text { wrist (msec) }\end{array}$}} & \multirow{2}{*}{\multicolumn{2}{|c|}{$\begin{array}{l}\text { Motor conduction velocity } \\
(\mathrm{m} / \mathrm{sec})\end{array}$}} & \multicolumn{4}{|c|}{ Sensory action potential } \\
\hline & & & & & \multicolumn{2}{|c|}{ median nerve } & \multicolumn{2}{|c|}{ ulnar nerve } \\
\hline & $\begin{array}{l}\text { median } \\
\text { nerve }\end{array}$ & $\begin{array}{c}\text { ulnar* } \\
\text { nerve }\end{array}$ & $\begin{array}{l}\text { median } \\
\text { nerve }\end{array}$ & $\begin{array}{l}\text { ulnar* } \\
\text { nerve }\end{array}$ & $\begin{array}{l}\text { latency } \\
(m s e c)\end{array}$ & $\begin{array}{l}\text { amplitude } \\
(\mu V)\end{array}$ & $\begin{array}{l}\text { latency } \\
(m s e c)\end{array}$ & $\begin{array}{l}\text { amplitude } \\
(\mu V)\end{array}$ \\
\hline \multicolumn{9}{|l|}{$\begin{array}{l}\text { Control subjects ( } 34) \\
\quad \text { (age 18-77 yr, mean } 47)\end{array}$} \\
\hline $\begin{array}{l}\text { Range } \\
\text { Mean } \pm S D\end{array}$ & $\begin{array}{c}2 \cdot 6-4 \cdot 9 \\
3 \cdot 4 \pm 0 \cdot 5\end{array}$ & $\begin{array}{r}2 \cdot 1-3 \cdot 7 \\
2 \cdot 6 \pm 0 \cdot 4\end{array}$ & $\begin{array}{c}49-66 \\
56 \cdot 9 \pm 5 \cdot 0\end{array}$ & $\begin{array}{c}48-61 \\
55 \cdot 7 \pm 4 \cdot 6\end{array}$ & $\begin{array}{l}2 \cdot 2-3 \cdot 8 \\
3 \cdot 0 \pm 0 \cdot 3\end{array}$ & $\begin{array}{c}9-40 \\
17 \cdot 9 \pm 7 \cdot 5\end{array}$ & $\begin{array}{c}2 \cdot 0-3 \cdot 4 \\
2 \cdot 6 \pm 0 \cdot 3\end{array}$ & $\begin{array}{c}6-36 \\
13 \cdot 7 \pm 6 \cdot 4\end{array}$ \\
\hline \multicolumn{9}{|c|}{$\begin{array}{l}\text { Carpal tunnel syndrome (234) } \\
\text { (age 19-87 yr, mean 54) }\end{array}$} \\
\hline $\begin{array}{l}\text { Range } \\
\text { Mean } \pm S D\end{array}$ & $\begin{array}{l}2 \cdot 7-14 \cdot 5 \\
5 \cdot 8 \pm 2 \cdot 0\end{array}$ & $\begin{array}{r}1 \cdot 8-5 \cdot 0 \\
3 \cdot 3 \pm 1 \cdot 0\end{array}$ & $\begin{array}{c}21-77 \\
48 \cdot 7 \pm 11 \cdot 5\end{array}$ & $\begin{array}{c}15-68 \\
50 \cdot 5 \pm 9 \cdot 7\end{array}$ & $\begin{array}{c}3 \cdot 0-6 \cdot 2 \\
4 \cdot 4 \pm 0 \cdot 7\end{array}$ & $\begin{array}{c}0-19 \\
4 \cdot 6 \pm 5 \cdot 0\end{array}$ & $\begin{array}{c}1 \cdot 9-5 \cdot 0 \\
3 \cdot 0 \pm 0 \cdot 6\end{array}$ & $\begin{array}{c}0-18 \\
7 \cdot 9 \pm 4 \cdot 3\end{array}$ \\
\hline $\begin{array}{l}\text { Significance of difference } \\
\text { (Student's } t \text { test) }\end{array}$ & $\begin{array}{c}\text { HS } \\
P<0.001\end{array}$ & $\begin{array}{c}\text { HS } \\
P<0.001\end{array}$ & $\begin{array}{c}\text { HS } \\
P<0.001\end{array}$ & $\begin{array}{c}\text { HS } \\
P<0.001\end{array}$ & $\begin{array}{c}\mathrm{HS} \\
\mathrm{P}<0.001\end{array}$ & $\begin{array}{c}\text { HS } \\
P<0.001\end{array}$ & $\begin{array}{c}\text { HS } \\
P<0.001\end{array}$ & $\begin{array}{c}\text { HS } \\
P<0.001\end{array}$ \\
\hline
\end{tabular}

* Ulnar nerve motor studies were performed in 100 cases. Latency measured to abductor digiti minimi muscle.

$\mathrm{HS}=$ highly significant.

TABLE 2

FREQUENCY OF ELECTROPHYSIOLOGICAL ABNORMALITIES IN 234 CASES OF CARPAL TUNNEL SYNDROME

\begin{tabular}{|c|c|c|c|c|c|c|}
\hline & \multicolumn{2}{|c|}{ Median nerve } & \multicolumn{2}{|c|}{$\begin{array}{l}\quad \text { Median nerve } \\
\text { Sensory action potential }\end{array}$} & \multicolumn{2}{|c|}{$\begin{array}{c}\text { Ulnar nerve } \\
\text { Sensory action potential }\end{array}$} \\
\hline & $\begin{array}{c}\text { Motor latency } \\
\text { from wrist } \\
(\text { msec })\end{array}$ & $\begin{array}{c}\text { Motor conduction } \\
\text { velocity } \\
(\mathrm{m} / \mathrm{sec})\end{array}$ & $\begin{array}{l}\text { latency } \\
(m s e c)\end{array}$ & $\begin{array}{c}\text { amplitude } \\
(\mu V)\end{array}$ & $\begin{array}{l}\text { latency } \\
(\text { msec) }\end{array}$ & $\begin{array}{c}\text { amplitude } \\
(\mu V)\end{array}$ \\
\hline $\begin{array}{l}\text { Criterion of abnormality } \\
\text { Frequency }(\%)\end{array}$ & $\begin{array}{r}>5 \cdot 0 \\
65 \cdot 0\end{array}$ & $\begin{array}{c}<47 \\
35 \cdot 4\end{array}$ & $\begin{array}{l}>4 \cdot 0 \\
88 \cdot 0\end{array}$ & $\begin{array}{l}<8 \cdot 0 \\
76 \cdot 5\end{array}$ & $\begin{array}{r}>4 \cdot 0 \\
4 \cdot 8\end{array}$ & $\begin{array}{l}<7 \cdot 0 \\
39 \cdot 3\end{array}$ \\
\hline
\end{tabular}

TABLE 3

NERVE CONDUCTION STUDIES IN CARPAL TUNNEL SYNDROME: COMPARISON OF CASES WITH NORMAL AND REDUCED MEDIAN NERVE MOTOR CONDUCTION VELOCITY IN THE FOREARM

\begin{tabular}{|c|c|c|c|c|c|c|}
\hline & \multirow{3}{*}{$\begin{array}{l}\text { Age } \\
(y r)\end{array}$} & \multirow{3}{*}{$\begin{array}{l}\text { Median motor } \\
\text { latency from } \\
\text { wrist } \\
(\text { msec })\end{array}$} & \multicolumn{4}{|c|}{ Sensory action potential } \\
\hline & & & \multicolumn{2}{|c|}{ Median nerve } & \multicolumn{2}{|c|}{ Ulnar nerve } \\
\hline & & & $\begin{array}{l}\text { latency } \\
\text { (msec) }\end{array}$ & $\begin{array}{l}\text { amplitude } \\
\quad(\mu V)\end{array}$ & $\begin{array}{r}\text { latency } \\
(m s e c)\end{array}$ & $\begin{array}{l}\text { amplitude } \\
(\mu V)\end{array}$ \\
\hline $\begin{array}{l}\text { Normal median motor conduction } \\
\text { velocity in forearm }(>47 \mathrm{~m} / \mathrm{sec})(146)\end{array}$ & $52 \cdot 2 \pm 12 \cdot 9$ & $5 \cdot 4 \pm 1 \cdot 3$ & $4.4 \pm 0.6$ & $5 \cdot 6 \pm 2 \cdot 2$ & $2 \cdot 9 \pm 0 \cdot 5$ & $8 \cdot 5 \pm 4 \cdot 4$ \\
\hline $\begin{array}{l}\text { Reduced motor conduction velocity in } \\
\text { forearm ( }<47 \mathrm{~m} / \mathrm{sec})(82) \\
\text { Significance of difference (Student's } \\
t \text { test) }\end{array}$ & $\begin{array}{c}56 \cdot 1 \pm \frac{12 \cdot 8}{S} \\
P<0.05\end{array}$ & $\begin{array}{l}6 \cdot 5 \pm 2 \cdot 3 \\
P \\
P<0.001\end{array}$ & $\begin{array}{c}4 \cdot 6 \pm 0 \cdot 7 \\
\stackrel{N S}{P}<0 \cdot 1\end{array}$ & $\begin{array}{l}3 \cdot 0 \pm 4 \cdot 2 \\
\mathrm{HS} \\
\mathrm{P}<0 \cdot 00\end{array}$ & $\begin{array}{l}3 \cdot 1 \pm 0 \cdot 7 \\
\quad \mathrm{NS} \\
\mathrm{P}<0 \cdot 1\end{array}$ & $\begin{array}{l}6.9 \pm 3.7 \\
\mathrm{P} \\
\mathrm{P}\end{array}$ \\
\hline
\end{tabular}

Mean figures are given with standard deviation.

$\mathrm{S}=$ Significant.

HS $=$ Highly significant

NS $=$ Not significant. 


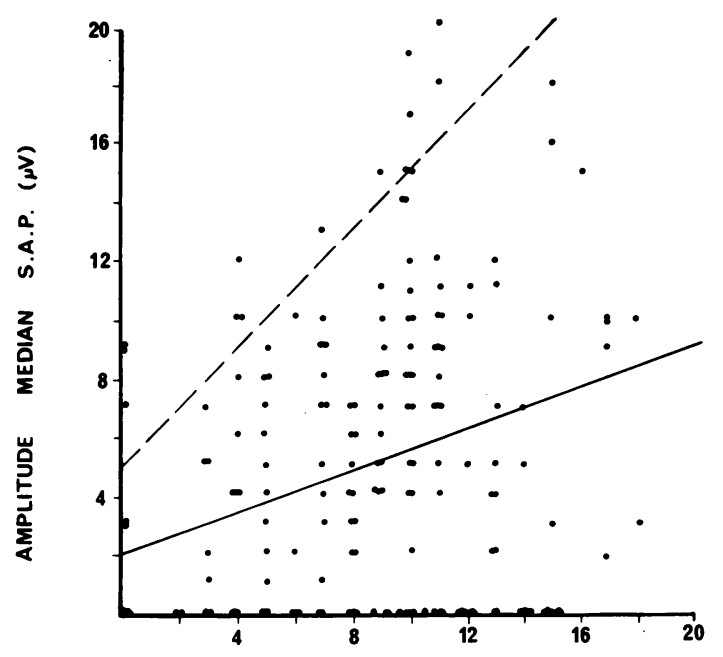

AMPLITUDE ULNAR S.A.P. ( $\mu$ V)

FIG. 2. Relationship of amplitude of ulnar nerve sensory action potential to amplitude of median nerve sensory action potential in patients with carpal tunnel syndrome. Solid line: regression line for carpal tunnel syndrome. Interrupted line: regression line for controls.

carpal tunnel syndrome was an incidental finding in the investigation of a generalized peripheral neuropathy; if they suffered from disorders such as diabetes, alcoholism, and chronic renal disease which predispose to peripheral neuropathy; and if there was clinical evidence of either radial or ulnar nerve lesions.

ELECTROPHYSIOLOGICAL TECHNIQUES Motor and sensory conduction in the median nerve and sensory conduction in the ulnar nerve were studied in all 234 cases (Gilliatt and Sears, 1958; Thomas, 1960). In 100 cases measurements of ulnar nerve motor conduction velocities were also made (Gilliatt and Thomas, 1960). In the determination of motor conduction velocity, concentric needle electrodes were used.

The electrical stimulus was a square wave of duration $0.2 \mathrm{msec}$ derived from a DISA Ministim. The recording electrodes were connected to a Tektronix FM122 preamplifier and the action potentials were displayed on the upper beam of a Tektronix 502A oscilloscope. A time scale derived from a Digitimer (Devices Limited) was displayed on the lower beam. Photographic records were made on $35 \mathrm{~mm}$ film. The temperature was measured on all controls and a large number of patients with carpal tunnel syndrome. The skin temperature in all cases was greater than $32^{\circ} \mathrm{C}$ on the forearm.

\section{RESULTS}

The results of nerve conduction studies in the median and ulnar nerves are summarized in Table 1 and the frequency of different types of abnormality are summarized in Table 2.

MEDIAN NERVE CONDUCTION The most common abnormalities found in the carpal tunnel syndrome were prolonged latency of the sensory action potential $(88 \%)$ and reduction in the amplitude of the sensory action potential $(76.5 \%)$. An increase in the terminal latency of motor fibres in the median nerve occurred in $65 \%$ of cases.

In two cases neither motor nor sensory conduction across the wrist could be demonstrated. In two other cases there was no motor conduction across the wrist but the sensory actiog potentials were abnormal.

In $35.4 \%$ of cases motor conduction velocit in the forearm segment was less than $47 \mathrm{~m} / \mathrm{sec}$.

ULNAR NERVE CONDUCTION The mean latence and amplitude of the ulnar sensory action. potential in the patients were $3.0 \mathrm{msec}(\mathrm{SD}, 0 . \overline{0}$ and $7.9 \mu \mathrm{V}(\mathrm{SD}, 4.3)$ which may be compared $\omega$ with those of $2.6 \mathrm{msec}(\mathrm{SD}, 0.3)$ and $13.7 \mu \mathrm{V}$ (SD, 6.4) in the controls. Both these differences are highly significant $(P<0.001)$. In $39.3 \%$ of cases the amplitude of the sensory action potential was less than $7 \cdot 0 \mu \mathrm{V}$; in $4.8 \%$ of cases the $\stackrel{\mathbb{Q}}{\unrhd}$ latency of the sensory action potential was $\overrightarrow{\overrightarrow{0}}$ greater than $4.0 \mathrm{msec}$.

The effect of age on the amplitude of the ulnar sensory action potential for both patients and controls is shown in Fig. 1. At all ages the regression line for the patients with carpal tunnelo syndrome has a lower value for amplitude than $\frac{0}{3}$ that for controls.

The relationship of the amplitude of the ulnar sensory action potential to the amplitude of the median sensory action potential is shown in Fig. 2. For control subjects there is a high degree $\frac{D}{2}$ of correlation $(r=0 \cdot 76)$. In carpal tunnel syndrome there is less correlation $(r=0.36)$ but the degree of correlation remains significant $(\mathrm{P}<\tilde{N}$ $0 \cdot 001$, Student's $t$ test). 


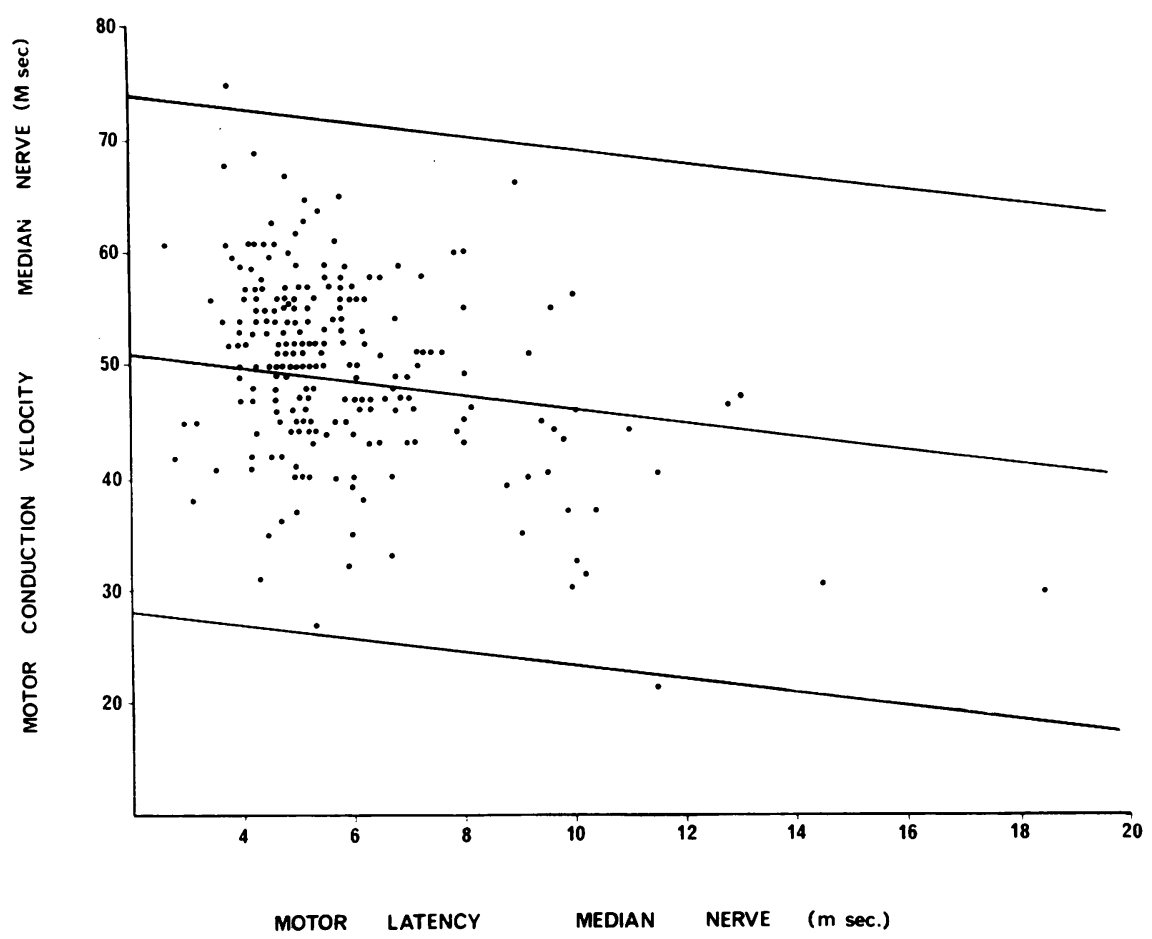

FIG. 3. Relationship of motor conduction velocity in forearm segment of median nerve to terminal latency in patients with carpal tunnel syndrome. Solid lines: regression line and two standard deviations above and below the mean.

In 100 patients ulnar nerve motor conduction velocity was measured (Table 1). The mean values for ulnar motor conduction velocity and motor latency were significantly different from controls $(P<0.001)$.

The selection of cases for ulnar nerve motor studies was biased towards those with ulnar sensory abnormalities. Forty-nine of the 100 patients had a reduced ulnar sensory potential amplitude compared with $38.3 \%$ for the whole series. Twenty-eight of these 49 were demonstrated to have an ulnar nerve lesion at the elbow according to the criteria of Gilliatt and Thomas (1960).

CARPAL TUNNEL SYNDROME WITH REDUCED MEDIAN NERVE MOTOR CONDUCTION VELOCITY IN FOREARM The relationship of median nerve motor latency to median nerve motor conduction velocity is shown in Fig. 3. It may be seen that motor conduction velocity is slower in patients with the long terminal latencies.

The characteristics of patients with normal and reduced median nerve motor conduction velocity are compared in Table 3. Those with proximal slowing were older and had a longer motor latency and smaller amplitude of the sensory action potential in the median nerve. All these differences were statistically significant. The median nerve sensory latency was prolonged though not to a significant level $(P<0 \cdot 1)$. The discrepancy may be explained by the fact that in the computation of mean latency, patients with an absent action potential cannot be included; this was the case in 46 of the 82 patients with proximal slowing, but in only 55 out of 146 cases with normal conduction above the wrist.

The relationship of the amplitude of the ulnar nerve sensory action potential to the median nerve motor conduction velocity is shown in 


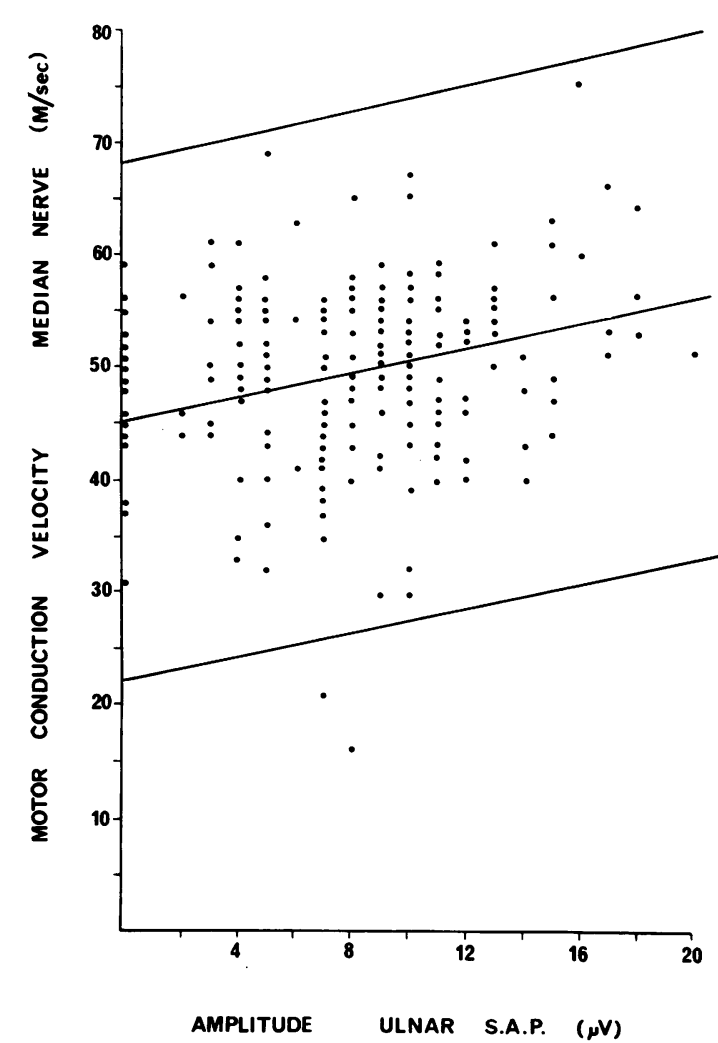

FIG. 4. Relationship of motor conduction velocity in median nerve to amplitude of ulnar nerve sensory action potential in patients with carpal tunnel syndrome. Solid lines: mean regression line, and two standard deviations above and below mean.

Fig. 4. As median nerve motor conduction velocity decreases, so does the amplitude of the ulnar nerve sensory action potential.

In Table 3 conduction in the ulnar nerve of two groups is compared. Those patients in whom there was proximal slowing of motor conduction in the median nerve had a significantly reduced amplitude of the ulnar nerve sensory action potential. The mean latency of the ulnar sensory action potential was greater in those with proximal median nerve slowing but the difference was not significant $(P<0 \cdot 1)$. Again, a greater proportion of those with proximal slowing $(9 / 82)$ than those with normal conduction $(13 / 146)$ had an absent ulnar nerve sensory action potential, the latency of which cannot be calculated.

\section{DISCUSSION}

There is little doubt that the patients under consideration in the present study suffered from the carpal tunnel syndrome. All presented with clinical features of the disorder, and in all cases there were electrophysiological abnormalities consistent with the diagnosis. The upper limit of the normal range of terminal motor latency in the median nerve was taken to be $5.0 \mathrm{msec}$ (Simpson, 1956; Thomas, 1960). The upper limit of the normal range of latency to peak of the sensory action potential in the median nerve was taken to be $4.0 \mathrm{msec}$ and the lower limit of the normal range of amplitude was $8 \mu \mathrm{V}$ (Gilliatt and Sears, 1958). The criteria for the electrophysiological diagnosis were therefore slightly more stringent than those of Thomas, Lambert, and Csuez (1967). All patients were excluded with clinical evidence of a generalized peripheral neuropathy, with lesions involving other nerves, or with disorders such as diabetes, alcoholism uraemia, or pernicious anaemia which predispose to peripheral nerve disease.

The frequency of abnormalities of conductiof found in the median nerve is similar to that found by other workers. Terminal motor latenç was prolonged in $65 \%$ of our patients, an latency of the sensory action potential was in creased in $88 \%$. The figures are very close to those obtained by Thomas et al. (1967) and Kemble (1968). Buchthal and Rosenfalck (1971) found slowing of motor conduction but not of sensory conduction above the wrist. The cause of the slowing of motor conduction in the median nerve above the level of the wrist is not clear. Thomas (1960) suggested that it may result from selective damage of large diameter fibres, or possibly from reduction in the diameter of all fibres above the level of the lesion. The findings of Anderson, Fullerton, Gilliatt, and Hern (1970) in guinea-pigs indicate that, at least in severe chronic lesions, reduction of fibre diameter above the level of compression is an important factor. Another factor which has not previously been taken into account is that there may be a subclinical neuropathy affecting the whole of the nerve. The present study in which it has been demonstrated that there is a significant correla- ? tion between the amplitudes of the ulnar nerve $N$ sensory action potential and the motor conduc- 
tion velocity in the median nerve supports the suggestion.

A statistically highly significant reduction in the mean amplitude of the ulnar nerve sensory action potential has been found in the patients studied with carpal tunnel syndrome. A reduction in the amplitude of the action potential below the lower limit of the normal range $(7 \mu \mathrm{V})$ was found in $39.3 \%$ of patients. This high incidence of ulnar nerve abnormalities has not been commented on previously. Some earlier workers did not report studies on the ulnar nerve (Simpson, 1956; Thomas, 1960) and others reported only motor conduction studies (Thomas et al., 1907). Kemble (1968) and Buchthal and Rosenfalck (1971) state that ulnar nerve sensory conduction was normal in their patients. Motor conduction velocities in the ulnar nerve were not determined on all our patients, but in over half the patients with abnormal ulnar nerve sensory action potentials on whom motor conduction studies were carried out the lesion was found to be at the elbow. Loong and Seah (1971) have suggested that measurement of the ratio of median to ulnar nerve sensory action potential amplitude may be valuable in the diagnosis of carpal tunnel syndrome. Although an associated ulnar nerve lesion would not alter the validity of such a test, it may be expected to reduce its sensitivity.

The reasons for the high incidence of ulnar nerve lesions in the present series are not clear. There may be some bias in the type of patients with symptoms of carpal tunnel syndrome referred to our clinic for conduction studies, but this has not been previously apparent. It is possible that a significant proportion of patients have an underlying subclinical neuropathy which predisposes them to entrapment neuropathies (Gilliatt and Willison, 1962). The finding that there is a significant correlation between the amplitudes of the median and ulnar nerve sensory action potentials, and that there is also a significant correlation between the motor conduction velocity in the median nerve and the amplitude of the ulnar nerve sensory action potential suggest that factors outside the carpal tunnel itself may be important in the pathogenesis of the syndrome and lend support to the idea of an underlying generalized neuropathy. A hereditary susceptibility to peripheral nerve pressure palsies occurs in some people (Earl, Fullerton, Wakefield, and Schutta, 1964) but it was clearly not the cause of the associated ulnar and median nerve lesions in our subjects.

\section{REFERENCES}

Anderson, M. H., Fullerton, P. M., Gilliatt, R. W., and Hern, J. E. C. (1970). Changes in the forearm associated with median nerve compression at the wrist in the guineapig. Journal of Neurology, Neurosurgery, and Psychiatry, 33, 70-79.

Buchthal, F., and Rosenfalck, A. (1971). Sensory conduction from digit to palm and from palm to wrist in the carpal tunnel syndrome. Journal of Neurology, Neurosurgery, and Psychiatry, 34, 243-252.

Dawson, G. D. (1956). The relative excitability and conduction velocity of sensory and motor nerve fibres in man. Journal of Physiology, 131, 436-451.

Earl, C. J., Fullerton, P. M., Wakefield, G. S., and Schutta, H. D. (1964). Hereditary neuropathy, with liability to pressure palsies. Quarterly Journal of Medicine, 33, 481498.

Gilliatt, R. W., and Sears, T. A. (1958). Sensory nerve action potentials in patients with peripheral nerve lesions. Journal of Neurology, Neurosurgery, and Psychiatry, 21, 109-118.

Gilliatt, R. W., and Thomas, P. K. (1960). Changes in nerve conduction with ulnar lesions at the elbow. Journal of Neurology, Neurosurgery, and Psychiatry, 23, 312-320.

Gilliatt, R. W., and Willison, R. G. (1962). Peripheral nerve conduction in diabetic neuropathy. Journal of Neurology, Neurosurgery, and Psychiatry, 25, 11-18.

Kemble, F. (1968). Electrodiagnosis of the carpal tunnel syndrome. Journal of Neurology, Neurosurgery, and Psychiatry, 31, 23-27.

Loong, S. C., and Seah, C. S. (1971). Comparison of median and ulnar sensory nerve action potentials in the diagnosis of the carpal tunnel syndrome. Journal of Neurology, Neurosurgery, and Psychiatry, 34, 750-754.

Simpson, J. A. (1956). Electrical signs in the diagnosis of carpal tunnel and related syndromes. Journal of Neurology, Neurosurgery, and Psychiatry, 19, 275-280.

Thomas, J. E., Lambert, E. H., and Cseuz, K. A. (1967). Electrodiagnostic aspects of the carpal tunnel syndrome. Archives of Neurology, 16, 635-641.

Thomas, P. K. (1960). Motor nerve conduction in the carpal tunnel syndrome. Neurology (Minneap.), 10, 1045-1050.

Thomas, P. K., Sears, T. A., and Gilliatt, R. W. (1959). The range of conduction velocity in normal motor nerve fibres to the small muscles of the hand and foot. Journal of Neurology, Neurosurgery, and Psychiatry, 22, 175-181. 